\title{
Respiratory and Irritant Health Effects of a Population Living in a Petrochemical-Polluted Area in Taiwan
}

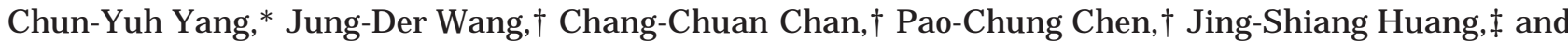 \\ Ming-Fen Cheng§

\begin{abstract}
*School of Public Health, Kaohsiung Medical College, Kaohsiung, Taiwan; †I nstitute of Occupational Medicine and Industrial Hygiene, College of Public Health, National Taiwan University, Taipe, Taiwan; łI nstitute of Statistical Science, Academia Sinica, Taipe, Taiwan; and §School of Public Health, Kaohsiung Medical College, Kaohsiung, Taiwan
\end{abstract}

Received J anuary 6, 1997

Reported herewith are the results from an ongoing study of outdoor air pollution and the health of persons living in the communities in close proximity to petrochemical industrial complexes. To determine if there is an excess of adverse health outcomes in the population exposed to petrochemical industrial emissions, a health survey was undertaken in 1996 in this area and in one reference area which has no local industrial emissions. The subjects were 436 adults (30-64 years of age) living in the Sanwei area (exposed area) and 488 in Taicei (reference area). For several indicators of respiratory health, including cough, wheezing, and chronic bronchitis, the prevalence rates were not significantly different between the study and the control populations. Acute irritative symptoms (eye irritation, nausea, throat irritation, and chemical odor perception) were significantly more common in the exposed area, particularly perception of chemical odors ( $84.6 \%$ vs $2.1 \%)$. It is concluded that exposure to petrochemical air emissions may be associated with increased rates of acute irritative symptoms. Future studies are needed to identify the potential role of petrochemical industrial emissions (particularly volatile organic compounds) in the genesis of acute irritative symptoms in a nearby petrochemical industrial area. $\odot 1997$ Academic Press

\section{INTRODUCTION}

Development of the basic petrochemical industry in Taiwan started some 25 years ago in 1968. According to the pollution reports compiled by the Environmental Protection Administration of Taiwan, the Republic of China, since 1983, nine serious air pollution episodes have occurred in petrochemical counties between 1971 and 1990 (EPA/ROC, 19841992). The pollutants emitted by these petrochemi- cal industries included not only the vinyl chloride monomer and polycyclic aromatic hydrocarbons (PAHs) which have been recognized as environmental carcinogens but also large quantities of criteria pollutants such as sulfur dioxide $\left(\mathrm{SO}_{2}\right)$, nitrogen dioxide $\left(\mathrm{NO}_{2}\right)$, and particulate matter $\left(\mathrm{PM}_{10}\right)$. An excess rate for liver cancer among males has been noted among those living in petrochemical industrial counties (PIC) (Yang et al., 1997), while the respiratory and irritant health effects of petrochemical industry air emissions on surrounding communities have not been well studied.

Petrochemical industries are large, usually isolated, sources of air pollution. Taiwan has 19 such petrochemical industrial complexes on the periphery of small communities (Yang et al., 1997). The small communities in the southern Taiwan in close proximity to petrochemical industrial complexes provide unique opportunities to evaluate the health effects of a single source of pollution. The petrochemical industrial complexes are the only large pollution sources in these communities with little air pollution from motor vehicle activity.

The objective of the present study was to determine whether there was an excess of adverse respiratory and irritant health outcomes in population wholive close to petrochemical manufacturing facilities. This report characterizes respiratory and irritant symptoms of population who lived in Sanwei (petrochemical exposed area) and in one reference area (Taicei) that was not in the proximity of petrochemical or other industrial emissions.

\section{MATERIALS AND METHODS}

Design

A cross-sectional survey was designed to determine the prevalence of respiratory and irritative 
symptoms in the population living near the petrochemical works (exposed area) compared with a control area in Taiwan.

\section{Defining the Study Population}

Lin-Yuan county is one of the largest petrochemical manufacturing centers in Taiwan. A prior hypothesis was that exposure to petrochemical industry emissions would be inversely related to the distance of primary schools from the petrochemical industrial complexes. The elementary school was chosen as a surrogate for residential location because elementary schools in Taiwan are communitybased and serve very small areas (usually of less than a $2-\mathrm{km}$ radius). The exposed area analyzed here consisted of three communities which are located in close proximity to the elementary school (Sanwei primary school) which has the shortest distance between the school and the geographic center of major petrochemical industry complexes in LinYuan. The exposed population consisted of all residents aged 30-64 years living in the exposed area. Hence, the exposed population resided in close proximity to the major petrochemical manufacturing industries in Lin-Yuan and with intense air pollution caused by the petrochemical emissions.

The control area were at Taicei county which was a relatively unpolluted area, about $120 \mathrm{~km}$ north of Lin-Y uan. This area is basically free of local sources of industrial air pollution and is felt to be remote from the influence of any significant source of air pollution by site visits. However, the Taiwan Plastic Group (the biggest petrochemical industry company in Taiwan) has announced plans to invest in the Taicei area, creating an another petrochemical manufacturing center. This announcement gives rise to an opportunity to compare the health effects of a new environmental air pollution setting. When the present survey was carried out, baseline health and environment data were collected to provide a framework for a prospective epidemiological monitoring program in the near future, but in this study, the data were collected as a reference basis in order to evaluate whether or not there is an increased prevalence of respiratory and irritant symptoms in a petrochemical industrial area. The control area analyzed in this study consisted of three communities which are located in close proximity to an elementary school (Taicei primary school) and where an air quality monitoring station has been established by the Environmental Protection Administration (EPA), a central governmental agency. The control population consisted of all residents aged 30-64 years living in close proximity to the primary school.

\section{Questionnaire}

A modified version of the American Thoracic Society Questionnaire (adult version) (Ferris, 1978) was administered to all of the study subjects by trained interviewers. For this study, some questions were added concerning acute irritative symptoms that had the potential to cause irritation. Interviewers had been trained prior to the study through lecture sessions as well as practice administration of the questionnaire. Each interviewer worked in both the exposed and control areas. The survey, including the administration of questionnaires, was carried out between April 1996 to J une 1996.

The health questionnaire inquired about chronic respiratory symptoms such as coughing, phlegm production, wheezing, shortness of breath, and chronic bronchitis. The chronic respiratory symptoms concerned were defined as follows: chronic cough, coughing part of the day or the entire day for at least 3 months per year; phlegm production, phlegm production during a part of a day or for an entire day for at least 3 months per year; wheezing, a condition of causing a wheezy or whistling sound on inspiration at least occasionally, apart from that caused by a cold or acute upper respiratory infection; chronic bronchitis, a cough and/or phlegm on most days for 3 months or more out of a year; dyspnea, having to stop for breath when walking at one's own pace on level ground.

A second set of questions focused on acute eye, nose, and throat irritation, nausea symptoms, and chemical odor perception potentially effected by exposure to irritants. These questions concerned the occurrence of symptoms during the 1-month period prior to the date on which the questionnaire was completed.

\section{Air Pollution Measurement}

Air pollution measurements were carried out by the EPA air quality monitoring stations at each of the two primary schools. The monitoring stations were fully automatic. The air pollution data $\left(\mathrm{SO}_{2}\right.$, $\mathrm{NO}_{2}$, and $\mathrm{PM}_{10}$ ) were retrieved from the air quality monitoring data banks of the EPA for the whole year 1995. $\mathrm{SO}_{2}$ was measured by means of a UV fluorescence instrument, $\mathrm{NO}_{2}$ by a chemiluminescent apparatus, and $\mathrm{PM}_{10}$ by a beta attenuation method.

\section{Statistics}

The prevalence of respiratory symptoms according to place of residence were analyzed by means of the $\chi^{2}$ test for examination of independence between two 
variables. To explore the relations between respiratory symptoms and the exposure areas, multiple logistic regression models (Hosmer and Lemeshow, 1989) were used in which the potential confounding factors were controlled. The adjusted odds ratios and their 95\% confidence intervals were computed. All statistical analyses were performed using the Statistical Analysis System.

\section{RESULTS}

There were 2036 and 1976 residents 30-64 years of age who were identified from the electorate lists of 1995 for the exposed and control area, respectively. Subjects were numbered and used for random sampling in each area. A random sample (one-third of the population) for the exposed and control area numbered 679 and 659, respectively. The response rates were higher in control area-64.2\% (436/679) of the representative sample in the exposed area and $74.1 \%$ (488/659) in the control area. In both areas, the respondents were questioned by door-to-door interviews.

As shown in Table 1, subjects in the exposed area and the control area were similar in mean age, distribution of current smoking habits, and years of residence at the current address but varied in education (lower in exposed area) and sex (more male subjects in exposed area). The subjects living in the exposed area reported a higher rate of occupation exposure to dust/fumes than the subjects living in the control area ( $21.1 \%$ vs $10.3 \%)$.

TABLE 1

\section{Demographic Characteristics of Study Subjects from} Sanwei (Exposed Area) and Taicei (Control Area)

\begin{tabular}{lll}
\hline \multicolumn{1}{c}{$\begin{array}{c}\text { Demographic } \\
\text { characteristics }\end{array}$} & $\begin{array}{c}\text { Taicei } \\
(\mathrm{n}=488)\end{array}$ & $\begin{array}{c}\text { Sanwei } \\
(\mathrm{n}=436)\end{array}$ \\
\hline $\begin{array}{l}\text { Mean age in years (SD) } \\
\text { Sex (\%) }\end{array}$ & $52.4(14.4)$ & $49.4(10.7)$ \\
$\quad$ Male & 43.2 & $52.3^{*}$ \\
$\quad$ Female & 56.8 & 47.7 \\
Education >high school (\%) & 26.0 & $15.8^{*}$ \\
Smoker (\%) & & \\
$\quad$ Current smoker & 66.6 & 63.0 \\
$\quad$ Ex-smoker & 4.1 & 3.9 \\
$\quad$ Never & 29.3 & 33.1 \\
Years of residence in & & \\
$\quad$ current address & & \\
$\quad>10$ years & 92.6 & 94.3 \\
$\quad$ １0 years & 7.4 & 5.7 \\
Occupational dust/fumes (\%) & & \\
$\quad$ Exposed & 10.3 & $21.1^{*}$ \\
$\quad$ Nonexposed & 89.7 & 78.9 \\
\hline
\end{tabular}

a SD, standard deviation.

$* \mathrm{P}<0.05$.
The subjects living in exposed area had higher rates of selected respiratory symptoms (cough, phlegm, wheezing, and chronic bronchitis) but had a lower rate of dyspnea. The differences in phlegm production and dyspnea were significant ( $P<0.05$ ). There were significant differences of acute irritative symptoms (eye irritation, nausea, and chemical odor perception) between the exposed and the control area (Table 2).

A number of potential confounding factors which could have influenced an association between air pollution and respiratory symptoms and acute irritative symptoms were examined in this study. These included age, sex, educational level, smoking status, length of residence in the respondent's current home, and self-reported occupational exposures. The results of the multiple logistic regression analyses are shown in Table 3. All models controlled for the potential confounders mentioned above. The adjusted odds ratios were mostly greater than the corresponding crude odds ratios, but were similar to the crude odds ratios. Phlegm production remained significantly more prevalent in the exposed area. Rates of acute irritative symptoms showed an association with the living area except for acute nose symptoms. The odds ratios calculated for acute irritative symptoms in exposed area are between 1.52 for throat symptom and 403.43 for chemical perception, as compared with 1.0 for control subjects.

The monitoring station in the exposed area

\section{TABLE 2}

Prevalences of Selected Health Outcomes and Unadjusted Odds Ratios for Study Subjects from Sanwei (Exposed Area) and Taicei (Control Area)

\begin{tabular}{|c|c|c|c|}
\hline Symptom & $\begin{array}{c}\text { Taicei } \\
\text { (\%) }\end{array}$ & $\begin{array}{c}\text { Sanwei } \\
(\%)\end{array}$ & $\begin{array}{l}\text { Odds ratio } \\
\left(95 \% \mathrm{Cl}^{\mathrm{a}}\right)\end{array}$ \\
\hline \multicolumn{4}{|c|}{$\begin{array}{l}\text { Chronic respiratory } \\
\text { symptoms }\end{array}$} \\
\hline Cough & 7.8 & 11.2 & $1.50(0.96-2.33)$ \\
\hline Phlegm & 5.9 & 10.8 & $1.91(1.18-3.10)^{*}$ \\
\hline Wheezing & 4.3 & 6.7 & $1.58(0.89-2.82)$ \\
\hline Dyspnea & 6.8 & 3.2 & $0.39(0.25-0.60)^{*}$ \\
\hline Chronic & & & \\
\hline bronchitis & 1.6 & 2.5 & $1.55(0.61-3.90)$ \\
\hline \multicolumn{4}{|l|}{$\begin{array}{l}\text { Acute irritative } \\
\text { symptoms }\end{array}$} \\
\hline Eyes & 10.9 & 18.9 & $1.90(1.31-2.76)^{*}$ \\
\hline Nose & 18.0 & 17.4 & $0.96(0.68-1.35)$ \\
\hline Throat & 13.3 & 17.9 & 1.42 (0.99-2.03) \\
\hline Nausea & 4.5 & 10.8 & $2.56(1.52-4.32)^{*}$ \\
\hline $\begin{array}{l}\text { Chemical odor } \\
\text { perception }\end{array}$ & 2.1 & 84.6 & 263.26 (133.61-518.70)* \\
\hline
\end{tabular}

a $95 \%$ confidence interval.

$* \mathrm{P}<0.05$. 


\section{TABLE 3}

Adjusted Odds Ratios for the Assocation between Selected Health Outcomes and Living Area

\begin{tabular}{lcc}
\hline \multicolumn{1}{c}{ Health indicator } & $\begin{array}{c}\text { Adjusted } \\
\text { odds } \\
\text { ratio }^{\mathrm{a}}\end{array}$ & \multicolumn{1}{c}{$95 \% \mathrm{Cl}^{\mathrm{b}}$} \\
\hline Chronic respiratory symptoms & & \\
$\quad$ Cough & 1.62 & $(0.99-2.64)$ \\
Phlegm & 2.01 & $(1.19-3.42)^{*}$ \\
Wheezing & 1.65 & $(0.88-3.10)$ \\
Dyspnea & 0.42 & $(0.26-0.68)^{*}$ \\
Chronic bronchitis & 1.63 & $(0.67-2.59)$ \\
Acute irritative symptoms & & \\
Eyes & 2.16 & $(1.43-3.25)^{*}$ \\
Nose & 0.97 & $(0.68-1.38)$ \\
Throat & 1.52 & $(1.05-2.20)^{*}$ \\
Nausea & 2.51 & $(1.45-4.35)^{*}$ \\
Chemical odor perception & 403.43 & $(181.27-880.07)^{*}$ \\
\hline
\end{tabular}

a Taicei (control area) as a reference group.

b $95 \%$ confidence interval.

$* p<0.05$.

showed consistently higher concentrations of $\mathrm{SO}_{2}$, $\mathrm{NO}_{2}$, and $\mathrm{PM}_{10}$ than the control area (Table 4).

\section{DISCUSSION}

Researchers have used many approaches in determining the health effects of air pollution. Holland et al. (1980) suggested that evaluation of the effects of individual sources of pollutions is the epidemiologic approach that best eliminates the effects of other variables. Unfortunately, such an approach is impossible in urban areas. The present study employs this approach in small communities of rural Taiwan. Lebowitz (1981) recommended spatiotemporal designs as useful strategies in surveillance of respiratory effects of point sources of pollution. In this study, an attempt to estimate health effects in the two areas with different pollution levels was made. A spatial approach was used in which multivariate statistical analyses were performed in order to control for possible confounding factors. As in other environmental studies (Bhopal et al., 1994; Dales et al., 1989; Symington et al., 1992), only estimates of ex-

\section{TABLE 4}

Summary of Air Pollution Data in Sanwei Primary School (Exposed Area) and Taicei Primary School (Control Area)

\begin{tabular}{lrcc}
\hline Pollutants $^{\mathrm{a}}$ & Taicei & Sanwei & P value \\
\hline $\mathrm{SO}_{2}(\mathrm{ppb})$ & $2.59(2.72)$ & $10.60(3.15)$ & $\varangle 0.05$ \\
$\mathrm{NO}_{2}(\mathrm{ppb})$ & $8.29(1.64)$ & $17.43(2.25)$ & $\varangle 0.05$ \\
$\mathrm{PM}_{10}\left(\mu \mathrm{g} / \mathrm{m}^{3}\right)$ & $62.79(1.82)$ & $93.57(1.92)$ & $\varangle 0.05$ \\
\hline
\end{tabular}

a Values are geometric mean (geometric standard deviation). posure for residents, based on community monitoring, were available.

The results show that in many respiratory respects the population living close to petrochemical manufacturing complexes (Sanwei) had a similar re spiratory health experience to that in the control area (Taicei). However, for a number of acute irritative symptoms (mainly eye irritation, throat irritation, nausea, and chemical odor perception), there were large differences. However, due to the limited population studied and the cross-sectional study design, the evidence cannot be considered conclusive.

In a previous study (Yang et al ., 1997), it was demonstrated that schoolchildren residing in petrochemical industrial area (Sanwei) have significantly more respiratory symptoms compared with a cohort living in a control area (Taicei). Thus, the current findings suggest that chronic exposure to petrochemical industrial emissions have a biologic effect on the respiratory system great enough to cause symptoms among children, who may be sensitive indicators of environmental pollution, but not among adults.

Since no other major industrial sources of air pollution existed close to the petrochemical industrial area or in the control area, it can be assumed that the petrochemical industrial complexes were the single contributor to local air pollution. In this context it is inferred that acute symptom differences between the study and the control areas were not caused by another external source of air pollution.

The stability of the population, evidenced by length of residence (almost all respondents resided in current home more than 10 years), indicates that exposure has indeed been of long duration. However, the choice of residential location reflects factors related to health. Families with higher incomes may avoid living near a petrochemical plant, and persons adversely affected may move away. In a crosssectional study, the bias introduced by personal choices as to place of residence cannot be fully detected or controlled.

Odor perception in the exposed area may signal exposure to toxicologically significant concentrations of hazardous materials. In a pilot study conducted by Chan (1995) in the exposed area, for example, airborne levels of benzene and other volatile organic compounds (VOCs) could be distinguished from background levels in a neighborhood city (a city near the exposed area). While the mechanisms are not well understood (Wallace, 1991), these VOC compounds may cause symptoms through direct irritation and neurotoxic effects (Nielsen and Alaire, 1982; Harving et al., 1991). Experimental human 
exposures to mixtures of volatile organic compounds also produce symptoms of eye, mucosal, and airway irritation (Molhave et al., 1986). Thus, the findings that irritative symptoms (i.e., "eye soreness or irritation" and "throat soreness or irritation") and autonomic symptoms (nausea) were associated with residence exposure to petrochemical industrial emissions are biologically plausible and are consistent with the limited available evidence.

In conclusion, the results of this study show that residents in Sanwei, a rural area exposed to petrochemical industrial air pollution, have statistically significant more acute symptoms (eye irritation, nausea, throat irritation, and odor perception) than those in Taicei, a low-pollution rural area. The local community's observations that emissions from the petrochemical industrial complexes affected their health are probably correct. The excess of acute symptoms observed in those living close to the petrochemical industrial complexes can be best explained as a result of their exposure to its emissions, especially the VOCs, although the concentration of VOCs is lacking in this study. Therefore, it is recommended that future studies seek to identify the potential role of VOCs in the genesis of acute irritative symptoms near petrochemical industrial areas.

\section{ACKNOWLEDGMENT}

This study was supported by a grant from the National Science Council, Executive Yuan, Taiwan (NSC-85-2621-P-037-001).

\section{REFERENCES}

Bhopal, R. S., Phillimore, P., Moffatt, S., and Foy C. (1994). Is living near a coking works harmful to health? A study of industrial air pollution. J. Epidemiol. Community Health 48, 237-247.

Chan, C. C. (1993). "The Monitoring of Ambient Volatile Organic
Compounds: A Pilot Study." Environmental Protection Administration. Taipei [EPA-82-L 104-09-07]

Dales, R. E., Spitzer, W. O., Suissa, S., Schechter, M. T., Tousignant, P., and Steinmetz, N. (1989). Respiratory health of a population living downwind from natural gas refineries. Am. Rev. Respir. Dis. 139, 595-600.

Environmental Protection Administration, Republic of China (1984-1992). “Annual Reports of Air pollution in Taiwan, 1983-1990." Environmental Protection Administration, Taipei.

Ferris, B. G. (1978). Epidemiology standardization project. Am. Rev. Respir. Dis. 118, 36-47.

Harving, H., Dahi, R., and Molhave, L. (1991). Lung function and bronchial reactivity in asthmatics during exposure to volatile organic compounds. Am. Rev. Respir. Dis. 143, 751-754.

Holland, W. W., Bennett, A. E., Cameron, I. R., Florey, C. D. V., Leeder, S. R., Swan, A. V., and Waller, R. E. (1980). E pidemiologic evidence and the United States air quality standards. Am. J. Epidemiol. 111, 458-459.

Hosmer, D. W., and Lemeshow, S. (1989). "Applied Logistic Regression." Wiley, New York.

Lebowitz, M. D. (1981). Respiratory indicators. Environ. Res. 25, 225-235.

Molhave, L., Bach B., and Pedersen, O. F. (1986). Human reactions to low concentrations of volatile organic compounds. Environ. Int. 12, 167-175.

Nielsen, G. D., and Alaire, Y. (1982). Sensory irritation and respiratory stimulation by airborne benzene and alkyl-benzenes. Toxicol. Appl. Pharmacol. 65, 459-477.

Symington, P., Coggon, D., and Holgate, S. (1992). Respiratory symptoms in children at schools near a foundry. Br. J . Indust. Med. 48, 588-591.

Wallace, L. A. (1991). Comparison of risks from outdoor and indoor exposure to toxic chemicals. Environ. Health Perspect. 95, 7-13.

Yang, C. Y., Wang, J . D., Chan, C. C., Hwang, J . S., and Chen, P. C. (1997). Respiratory symptoms of primary school children living in a petrochemical polluted area in Taiwan. Pediatr. Pulm.

Yang, C. Y., Chiu, H. F., Chiu, J . F., Kao, W. Y., Tsai, S. S., and Lan, S. J . (1997). Cancer mortality and residence near petrochemical industries in Taiwan. J . Toxicol. Environ. Health 50, 265-273. 